\title{
Insect Elicitors and Exposure to Green Leafy Volatiles Differentially Upregulate Major Octadecanoids and Transcripts of 12-Oxo Phytodienoic Acid Reductases in Zea mays
}

\author{
Jürgen Engelberth, Irmgard Seidl-Adams, Jack C. Schultz, and James H. Tumlinson \\ Center for Chemical Ecology, Department of Entomology, The Pennsylvania State University, University Park, PA 16802, U.S.A. \\ Submitted 17 April 2006. Accepted 28 January 2007.
}

The induction of jasmonic acid (JA) is one of the major signaling events in plants in response to insect herbivore damage and leads to the activation of direct and indirect defensive measures. Green leafy volatiles, which constitute a major portion of volatile organic compounds, often are released in response to insect herbivore attack and have been shown to significantly activate JA production in exposed corn (Zea mays) seedlings, thereby priming these plants specifically against subsequent herbivore attack. To explore the factors determining the specificity of the octadecanoid signaling pathway in corn, we analyzed qualitative and quantitative changes in major octadecanoids. The time course and the amount of induced JA and 12-oxophytodienoic acid levels in corn seedlings were strikingly different after wounding, application of caterpillar regurgitant, or treatment with cis-3-hexenyl acetate (Z-3-6:AC). Exposure to Z-3-6:AC induced accumulation of transcripts encoded by three putative 12-oxophytodienoate10,11-reductase genes (ZmOPR1/2, ZmOPR5, and ZmOPR8). Although changes in ZmOPR5 RNAs were detected only after exposure to Z-3-6:AC, $\mathrm{ZmOPR1/2}$ RNAs and ZmOPR8 RNAs also were abundant after treatment with crude regurgitant elicitor or mechanical damage. The physiological implications of these findings in the context of plant-insect interactions are discussed.

Additional keywords: gene expression, OPR.

The response of plants to insect herbivory includes various defensive measures such as the production of proteinase inhibitors and toxic secondary metabolites, and the release of volatile organic compounds (VOC) (Gatehouse 2002). VOC are derived from shikimate, terpenoid, and fatty-acid products (Pare and Tumlinson 1997, 1999), and have been shown to be a very effective countermeasure by repelling further infestation (DeMoraes et al. 2001) and attracting predators and parasites of the attacking herbivore (Dicke et al. 1990; McCall et al. 1993, 1994; Turlings et al. 1990). Most if not all of these countermeasures appear to involve increases in the signal molecule jasmonic acid (JA) (Gatehouse 2002), which is derived from

Corresponding author: J. Engelberth; E-mail: jurgen.engelberth @utsa.edu

Current address of J. Engelberth: Department of Biology, University of Texas at San Antonio, One UTSA Circle, San Antonio 78249. linolenic acid through the octadecanoid signaling pathway (Fig. 1) (Schaller 2001; Schaller et al. 2004).

Initially, oxygen is added by a lipoxygenase (LOX) in position 13 of linolenic acid. The resulting 13-hydroperoxy linolenic acid is dehydrated by allene oxide synthase (AOS) to the very unstable allene oxide, which is rapidly and stereospecifically transformed by allene oxide cyclase (AOC) into the 9S,13Senantiomer of 12-oxo-phytodienoic acid (12-OPDA) in plastids. Then, 12-OPDA is transferred to the peroxisome by an ATPbinding cassette (ABC) transporter (Theodoulou et al. 2005), where the olefinic bond in the pentacyclic ring is reduced by 12-oxo-phytodienoate 10,11-reductase (OPR). Three consecutive $\beta$-oxidations follow eventually leading to JA (Cruz Castillo et al. 2004; Li et al. 2005).

It has been found that fatty acid/amino acid conjugates (FACs) in the oral secretions of insect herbivores elicit JA production as well as some typical defense responses when applied to artificial wounds (Halitschke et al. 2001; Schittko et al. 2000; Schmelz et al. 2001). The best characterized FAC is a glutamine/17-hydroxy linolenic acid conjugate, termed volicitin, which elicits octadecanoid signaling and VOC synthesis when applied to corn (Zea mays) (Schmelz et al. 2001). First described by Alborn and associates (1997), this compound seems to be the most active elicitor in the corn system within this group of insect-produced elicitors (Alborn et al. 1997; Turlings et al. 2000).

Another LOX-derived pathway leads to the production of so called green leafy volatiles (GLV) and traumatin. 13-Hydroperoxy linolenic acid is cleaved by the enzyme hydroperoxide lyase (HPL), resulting in cis-3-hexenal (Z-3-6:AL) and $\omega$-oxodecenoic acid. Further processing of Z-3-6:AL by alcohol dehydrogenase, acetylation, and isomerization leads to the production of the remaining $\mathrm{C}_{6}$ components such as cis-3-hexenol (Z-3-6:OL), cis-3-hexenyl acetate (Z-3-6:AC), and the respective trans-2-enantiomers. The $\mathrm{C}_{12}$ component $\omega$-oxo-decenoic acid is further processed to traumatin, which has long been hypothesized to play an important role in the wound response of plants (English and Bonner 1937). GLV almost immediately are released locally after wounding (Hatanaka 1993), but also can be produced and released systemically as a response to herbivore damage (Turlings and Tumlinson 1992, Pare and Tumlinson 1997; Röse et al. 1996).

GLV have been shown to act as signals in plant-plant communications after insect herbivore attack (Arimura et al. 2000; Bate and Rothstein 1998; Engelberth et al. 2004; Farag and Pare 2002; Farag et al. 2005; Ruther and Fürstenau 2005; Ruther and Kleier 2005). Exposing plants to physiological 
concentrations of GLV has been shown to induce defense-related gene expression and the release of VOC. However, these responses are very moderate compared with actual insect herbivore damage or application of JA (Arimura et al. 2000; Farag and Pare 2002). Exposing corn plants to GLV elicits immediate JA accumulation and, more importantly, enhances subsequent JA production and JA-signaled responses upon insect herbivore attack (Engelberth et al. 2004). This priming effect is specific for elicitor-induced JA, whereas wound-induced JA is not affected (Engelberth et al. 2004). GLV also trigger direct defense responses, such as defense gene activation and phytoalexin production, in plants attacked by insect herbivores or pathogens (Farag et al. 2005; Halitschke et al. 2004; Hildebrand et al. 1993, Kishimoto et al. 2005; Zeringue 1992). However, it is unclear whether or not these direct responses are mediated through the same signaling pathways that have been shown to be involved in the priming process.

Although all genes responsible for the production of JA have been thoroughly characterized in Arabidopsis, our knowledge about genes and proteins involved in the biosynthesis of octadecanoids in corn is very limited. For example, at least 13 LOX genes have been identified in corn, yet it is unclear which of these is responsible for producing the correct 13-hydroperoxylinolenic acid that eventually is converted to JA or processed to result in GLV. Also, eight different $O P R$ genes recently have been identified in corn by Zhang and associates (2005). OPR, which is the enzyme that catalyzes the reduction of the cyclopentanone moiety in 12-OPDA, belongs to a class of enzymes closely related to the yeast old yellow enzyme, a flavo-protein with the general activity of reducing double bonds in $\alpha, \beta$-unsaturated carbonyls (Schaller and Weiler 1997a

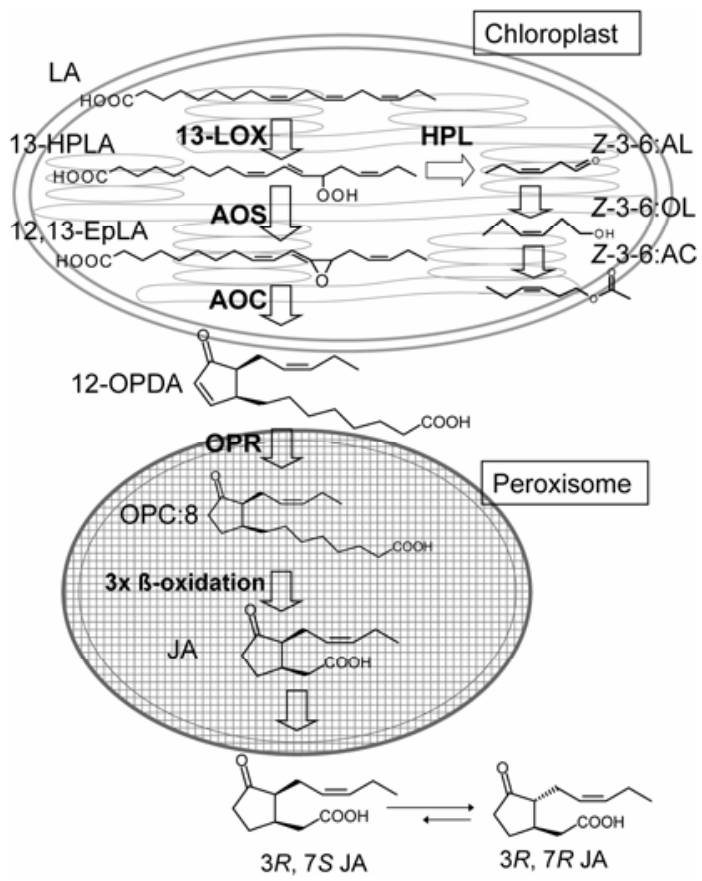

Fig. 1. Octadecanoid signaling pathway leading to jasmonic acid (JA) and green leafy volatiles (GLV). For each step the respective enzyme is shown in bold type: LOX, lipoxygenase; AOS, allene oxide synthase; AOC allene oxide cyclase; OPR, 12-oxo-phytodienoate reductase. Intermediates of the octadecanoid signaling pathway: LA, linoleic acid; 13-HPLA, 13S-hydroperoxy linoleic acid; 12,13-EpLA, 12,13 epoxy linoleic acid; 12-OPDA, 12 oxophytodienoic acid; OPC:8, 10,11 dihydro 12-oxophytodienoic acid; JA, jasmonic acid. Additionally, the pathway for the production of GLV is shown: HPL, hydroperoxide lyase; Z-3-6:AL, cis-3-hexen-1-al; Z-3-6:OL, cis-3-hexen-1-ol; Z-3-6:AC, cis-3-hexen-1-yl acetate. 3R, 7S-JA (commonly referred to as $c i s-\mathrm{JA}$ ) is supposedly the active enantiomer. and b; Strassner et al. 1999). Several OPRs have been identified to date in various plant species (Schaller et al. 2004). In Arabidopsis, three OPRs (AtOPR1, AtOPR2, and AtOPR3) have been cloned and further characterized (Biesgen and Weiler 1999; Schaller and Weiler 1997a and b). The expression of all three AtOPRs can be induced by methyl jasmonate. However, only AtOPR3 (and its homolog in tomato, LeOPR3) has a high preference for the enantiomerically correct substrate $9 \mathrm{~S}, 13 \mathrm{~S}$ 12-OPDA, suggesting that this isoenzyme is the one responsible for cis (+)-JA production, which is supposedly the biologically active form (Schaller et al. 2000). AtOPR1 and -2 do not exhibit this substrate specificity, and, although both are induced by wounding and UV light, exhibit a different organ-specific distribution (Biesgen and Weiler 1999). In corn, Zhang and associates (2005) showed that the eight $O P R$ genes $(Z m O P R I$ to $Z m O P R 8)$ are differentially expressed depending on the developmental stage of the plant, the organ in which they are expressed, whether they are expressed in response to JA or salicylic acid (SA), or after infection with various pathogens. According to their study, ZmOPRl and ZmOPR2 are highly inducible by SA and pathogen infection and, thus, seem to play a role in the defense response. ZmOPR6 to ZmOPR8 appear to be wound responsive, and expression also is stimulated by JA application. No induction of $\mathrm{ZmOPR} 3$ to $\mathrm{ZmOPR} 5$ has been found after pathogen infection or treatment with SA and JA. However, contrary to AOS and AOC, commonly described as bottleneck enzymes for the octadecanoid signaling pathway (Laudert and Weiler 1998; Ziegler et al. 2000), the physiological roles of OPRs in planta are not quite clear. As described before, only OPR3 in Arabidopsis and tomato have a preference for the correct 9S, 13S enantiomer of 12-OPDA. And although other OPRs also can reduce this enantiomer, the specificity is much lower and strongly suggests other functions within the plant cell. Breithaupt and associates (2001) found that AtOPR1 reduces a great variety of low molecular weight compounds with the only common feature of having an $\alpha, \beta$ unsaturated carbonyl. These compounds are highly reactive and serve as Michael acceptors, thereby significantly altering the functionality of cellular structures, and OPRs currently are discussed as major regulators in this process (Breithaupt et al. 2001; Schaller et al. 2004).

Although the octadecanoid pathway has been studied for more than 20 years (Schaller et al. 2004), how it regulates different developmental processes, perception of mechanical stimuli, and selectively activates defensive responses is not well understood. Also, other products of the octadecanoid signaling pathway such as 12-OPDA have been shown to trigger certain specific defense responses (Stintzi et al. 2001; Taki et al. 2005). The induction of JA by beet armyworm crude regurgitant (CRE), mechanical damage, or exposure to GLV as well as the specific interaction of these stimuli prompted us to start a more comprehensive analysis of octadecanoid signaling in corn. In addition to a thorough analysis of relevant octadecanoids, we focused our research on the expression of $O P R$ genes because of their potential to also be involved in processes not directly related to octadecanoid signaling. Distinct differences in the octadecanoid profiles were found, suggesting a more sophisticated regulation of this pathway than hitherto thought. Also, the selective accumulation of ZmOPR RNAs in response to the different treatments chosen for this analysis is described, with GLVs being a major regulator in this process.

\section{RESULTS}

\section{Profiling of JA and 12-OPDA.}

We compared the octadecanoid profiles and timing of induction in different sections of corn leaves, local, distal, and basal, 
induced by three different procedures. They were exposed to cis-3-hexenyl acetate (Z-3-6:AC) as a major representative of GLV, wounding, by far the best described event to elicit the octadecanoid pathway, and application of CRE to a wound site as a mimic of insect herbivory. A first study revealed that the application of CRE to wounded corn leaves not only increased JA production locally compared with a wounded control but also induced JA in distal parts of the corn leaf, whereas wound-induced JA production was a local event, affecting only the tissue adjacent to the damage site (Fig. 2B through D). The distal accumulation of JA basically can be attributed to volicitin and other, structurally related elicitors in the CRE. Volicitin elicited increased JA levels locally and distally from the application site equal to those after treatment with CRE (Fig. $2 \mathrm{~A}$ and $\mathrm{B}$ ).

For wounding or elicitation by $\mathrm{CRE}$ and volicitin, no increases in JA levels basal from the treatment site were detected (Fig. 2A through C). In contrast to wounding or application of CRE, corn plants responded to exposure to GLV by increasing JA throughout the exposed plant (Fig. 3). Comparing the time courses of JA and 12-OPDA production after all of these treatments showed further significant differences in the timing, quality, and quantity of these important intermediates of the octadecanoid pathway. In seedlings exposed to Z-3-6:AC, JA peaked at $10 \mathrm{~min}$ after the onset of the stimulus $(44 \mathrm{ng} / \mathrm{g}$ fresh weight [FW] for cis-JA and $8 \mathrm{ng} / \mathrm{g} \mathrm{FW}$ for trans-JA) and then declined rapidly, reaching normal resting levels again after $2 \mathrm{~h}$

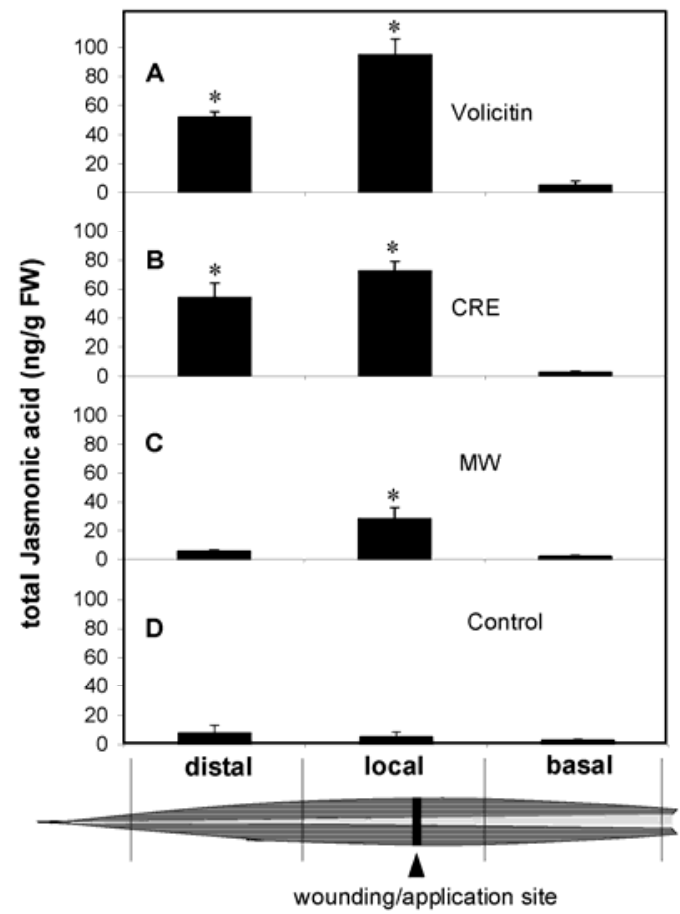

Fig. 2. Induction of jasmonic acid in different parts of a corn leaf. A schematic corn leaf has been added to demonstrate the experimental setup. A, Elicitation with volicitin. B, Elicitation with crude regurgitant elicitor (CRE). C, Mechanical wounding (MW). D, Control plants. A and B, The second leaf of a three-leaf corn plant was wounded approximately $7 \mathrm{~cm}$ above the base of the leaf (arrowhead $\boldsymbol{\Delta}$ ). Three segments (one consisting of the damaged area [local], one immediately below the local segment [basal], and one upward from the wounded segment [distal], all approximately $2.5 \mathrm{~cm}$ in length) of this leaf were taken for analysis $30 \mathrm{~min}$ after the onset of the stimulus. D, For control samples, corresponding leaf segments from control plants were taken to allow for exact comparison. Results are based on two independent studies, each performed with four biological replicates. Error bars represent standard deviation. A Student $t$ test was used for proof of significance $(*, P \leq 0.05)$ compared with the respective control.
(2.4 ng/g FW for cis-JA and $6 \mathrm{ng} / \mathrm{g} \mathrm{FW}$ for trans-JA) (Fig. 4A). The maximum JA production after wounding was measured after $30 \mathrm{~min}(60 \mathrm{ng} / \mathrm{g} \mathrm{FW}$ for $\mathrm{cis}$-JA and $13 \mathrm{ng} / \mathrm{g} \mathrm{FW}$ for trans-JA) (Fig. 4A), and higher levels of JA were maintained for at least $6 \mathrm{~h}$ compared with control plants (data not shown). Elicitation of JA by application of CRE to a wounded site followed a similar curve in the local and distal part of the treated leaf. Maximum induction was measured after 60 min with a twofold higher local JA level (90 ng/g FW for cis-JA and 35 ng/g FW for trans-JA) (Fig. 4A) compared with the distal response (54 ng/g FW for cis-JA and $17 \mathrm{ng} / \mathrm{g}$ FW for trans-JA) (Fig. 4A). This was followed by a rapid decline in both parts of the leaf. For all time courses, the maximum level of cis-JA preceded the peak of trans JA. Comparing the induction of 12OPDA by the different treatments clearly showed that this compound was induced only locally as a direct response to wounding. CRE application, which also included wounding (63 ng/g FW for cis-12-OPDA and $34 \mathrm{ng} / \mathrm{g}$ FW for trans-12OPDA, both after $60 \mathrm{~min}$ ) (Fig. 4B) and wounding alone (36 $\mathrm{ng} / \mathrm{g} \mathrm{FW}$ for cis-12-OPDA and $12 \mathrm{ng} / \mathrm{g} \mathrm{FW}$ for trans-12OPDA) (Fig. 4B), showed elevated levels of 12-OPDA locally with a time course almost identical to that of JA with these treatments. Free 12-OPDA levels were not increased by exposure to Z-3-6:AC (Fig. 4B) or in distal parts of the leaf by CRE application (Fig. 4B).

To test the priming effect of Z-3-6:AC on other treatments leading to the induction of JA, corn plants were pretreated by exposure to Z-3-6:AC vapors overnight (15 h). After overnight exposure to Z-3-6:AC, the resting levels of JA in these plants were the same as in the control plants $(8 \mathrm{ng} / \mathrm{g} \mathrm{FW})$. CRE or pure volicitin then was applied to the plants as a mimic of actual caterpillar feeding. Other plants were either mechanically damaged or reexposed to Z-3-6:AC. Priming with Z-36:AC had no effect on induced JA levels in wounded or plants treated by a second application of Z-3-6:AC (Fig. 5). However, preexposure to Z-3-6:AC did significantly effect induced JA levels in CRE-treated plants. At 45 min after induction with CRE, the level of endogenous JA rose in control plants to 106 ng/g FW compared with $199 \mathrm{ng} / \mathrm{g} \mathrm{FW}$ in Z-3-6:AC-pretreated plants. Using pure volicitin as the elicitor led to the same results as treatment with CRE (Fig. 5).

\section{Transcript levels of octadecanoid-related genes after} wounding, application of CRE, and exposure to Z-3-6:AC.

Although all treatments described above resulted in elevated JA levels, the pathways leading to this increase appeared to be significantly different. In a first approach to further characterize these differences, we compared changes in RNA levels of

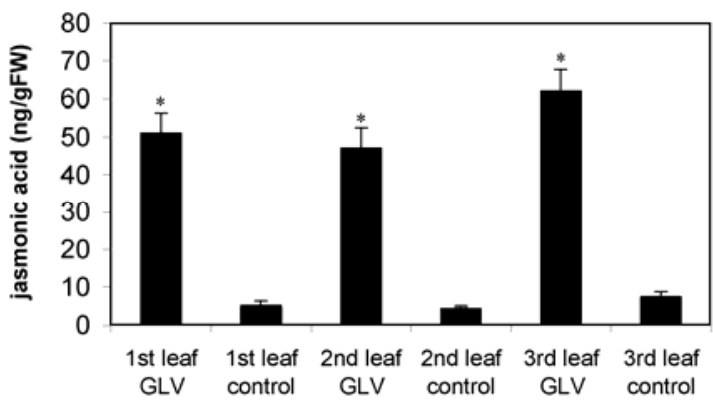

Fig. 3. Induction of jasmonic acid (JA) after exposure to green leafy volatiles (GLV) for $30 \mathrm{~min}$ in different leaves of a 14-day-old corn seedling (same as above). First leaf is the oldest leaf. For all graphs, total JA per milligram of plant material is shown. Results are based on one study performed with three biological replicates. Error bars represent standard deviation. A Student $t$ test was used for proof of significance $(* P \leq 0.05)$ compared with the respective control. 
genes potentially related to octadecanoid signaling. We analyzed the genes induced over a period of $120 \mathrm{~min}$ after exposure to Z-3-6:AC, mechanical wounding, and elicitation by CRE locally and distal from the application site. Plant material was collected after 0,60 , and 120 min and mRNA was prepared for semiquantitative reverse-transcription polymerase chain reaction (RT-PCR). Sequence information and primers were taken from Frey and associates (2004) for ZmAOS and $Z m A O C$. Primers for $Z m O P R$ s either were designed from published sequences by Zhang and associates (2005) or taken from expressed sequence tags available in the TIGR database. Additionally, time courses for total JA and 12-OPDA were added to allow for better correlation between the octadecanoid profile and the transcript levels of the respective gene. Results of these experiments are shown in Figure 6 and Table 1. ZmAOS mRNA resting levels were not detectable, but did rapidly increase within $60 \mathrm{~min}$ after stimulation and reached a maximum after $120 \mathrm{~min}$. For $Z m A O C$, resting levels of transcripts were found to be higher than those for $Z m A O S$, but otherwise followed the same trend after mechanical wounding or treatment with Z-3-6:AC and CRE.

The response of the $O P R$ genes tested in this study was distinctly different from $A O S$ and $A O C$ induction. ZmOPR5 was induced by exposure to Z-3-6:AC, and neither wounding nor elicitation with CRE increased the transcript levels of this gene, even at later time points ( $6 \mathrm{~h}$ ) (data not shown). $Z m O P R I / 2$ was induced by Z-3-6:AC and also in response to CRE elicitation, whereas wounding had less effect on the transcript level. With CRE application, transcript levels of $\mathrm{ZmOPRI/2}$ increased both locally and distally; however, the maximum RNA levels were reached distally in only $60 \mathrm{~min}$ compared with $120 \mathrm{~min}$ for the maximum local response. $Z m O P R 8$, which exhibits a high identity to AtOPR3, was induced by Z-3-6:AC, but also by wounding. Treatment with CRE locally increased the RNA levels of ZmOPR8, but not distal from the application site (Fig. 6). Despite the high identity between $\mathrm{ZmOPR7}$ and $\mathrm{ZmOPR} 8$, we were
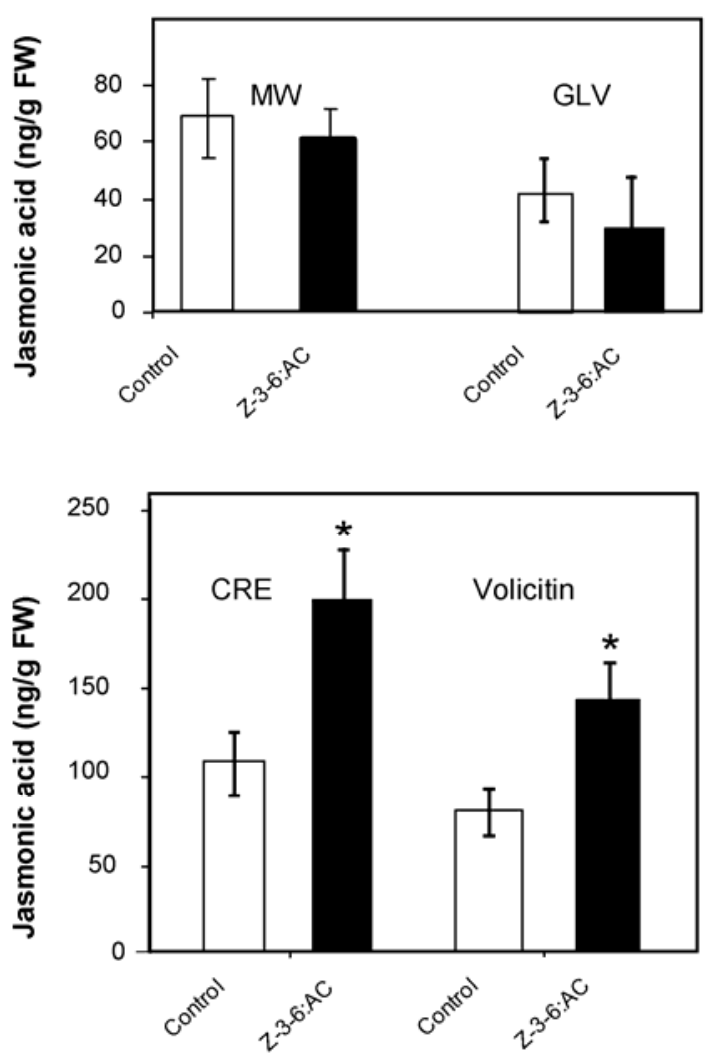

Fig. 5. Effect of previous exposure to Z-3-6:AC on total jasmonic acid JA levels by mechanical wounding (MW), exposure to Z-3-6:AC green leafy volatiles (GLV), elicitation with crude regurgitant (CRE), and elicitation with pure volicitin. Corn seedlings were pretreated with Z-3-6:AC overnight $(15 \mathrm{~h})$ and then treated as described above for $45 \mathrm{~min}$. Results are based on one study performed with four biological replicates. Error bars represent standard deviation. A Student $t$ test was used for proof of significance $(*, P \leq 0.05)$
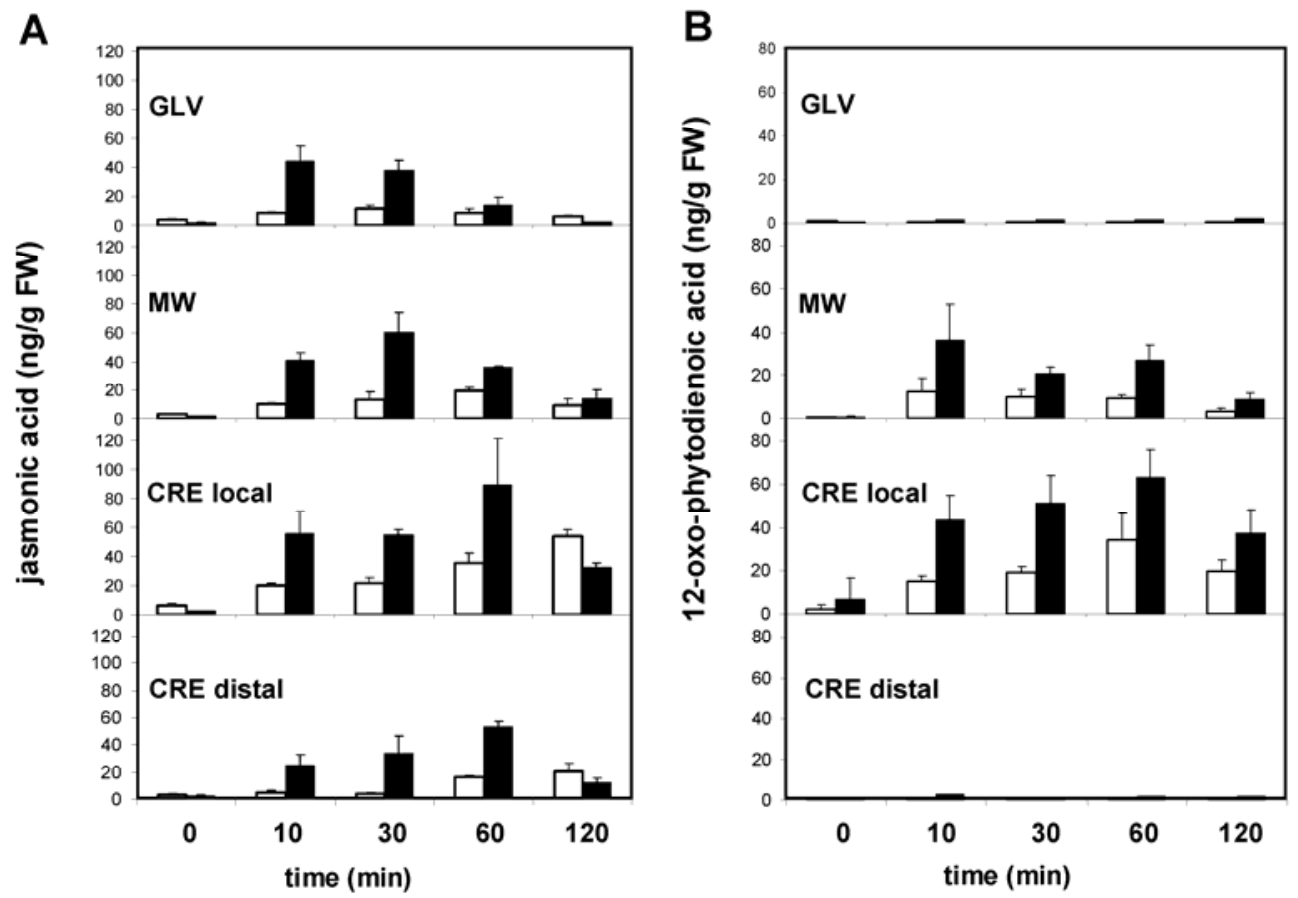

Fig. 4. Induction of jasmonic acid (JA) and 12-oxo-phytodienoic acid (12-OPDA) by various treatments in corn (Zea mays). A, JA levels after exposure to Z3-6:AC, mechanical wounding (MW), and CRE treatments at the site (CRE local) and distal (CRE distal) to the site of CRE application. For all treatments, cis-JA (black) and trans-JA (white) is shown. B, 12-OPDA levels after exposure to Z-3-6:AC, mechanical wounding, and crude regurgitant (CRE) treatments at the site (CRE local) and distal (CRE distal) to the site of CRE application. For all treatments, cis-12-OPDA (black) and trans-12-OPDA (white) is shown. Results are based on three independent studies each performed with four biological replicates. Error bars represent standard deviation. 
able to generate gene-specific primers for ZmOPR7. However, we were not able to see any abundance or increased levels after the treatments described herein. We were, however, able to detect $Z m O P R 7$ on the genomic level, indicating that our primers did work properly. Also, none of the above-described treatments affected the RNA levels of ZmOPR3, ZmOPR4, and ZmOPR6 (Table 1).

\section{ZmOPR enzyme activity in crude protein extracts.}

The induction of different $O P R$ s by GLV suggested that they might play an important role in the priming process, resulting in increased JA levels (Engelberth et al. 2004). And, indeed, when corn plants were treated with GLV overnight, a change in OPR enzyme activity was measured by using racemic 12 OPDA as the substrate. Compared with control plants, ZmOPR activity almost doubled in Z-3-6:AC-exposed plants when expressed as changes in ratio between 10,11 dihydro 12-oxophytodienoic acid (OPC) and 12-OPDA (Fig. 7).

\section{DISCUSSION}

The activation of JA in plants under insect-herbivore attack appears to be the most important signaling event directly or indirectly related to the induction of effective defensive measures of the plant (Gatehouse 2002). In addition to the production of proteinase inhibitors and toxic secondary metabolites, which directly affect the attacking insect herbivore, induced JA often causes the plant to release VOC such as terpenes, products of the shikimic acid pathway, and degradation products of $\mathrm{C}_{18}$ fatty acids, commonly referred to as GLV (Pare and Tumlinson 1997, 1999). A major function of these VOC is to serve as signals for predators and parasites of the attacking herbivore which allows them to cue in on their prey, a phenomenon generally referred to as tritrophic interactions (DeMoraes et al. 2001; Dicke et al. 1990; McCall et al. 1993, 1994; Turlings et al. 1990). Additionally, it has been shown that GLV can act as signals in interplant communication (Engelberth et al. 2004;

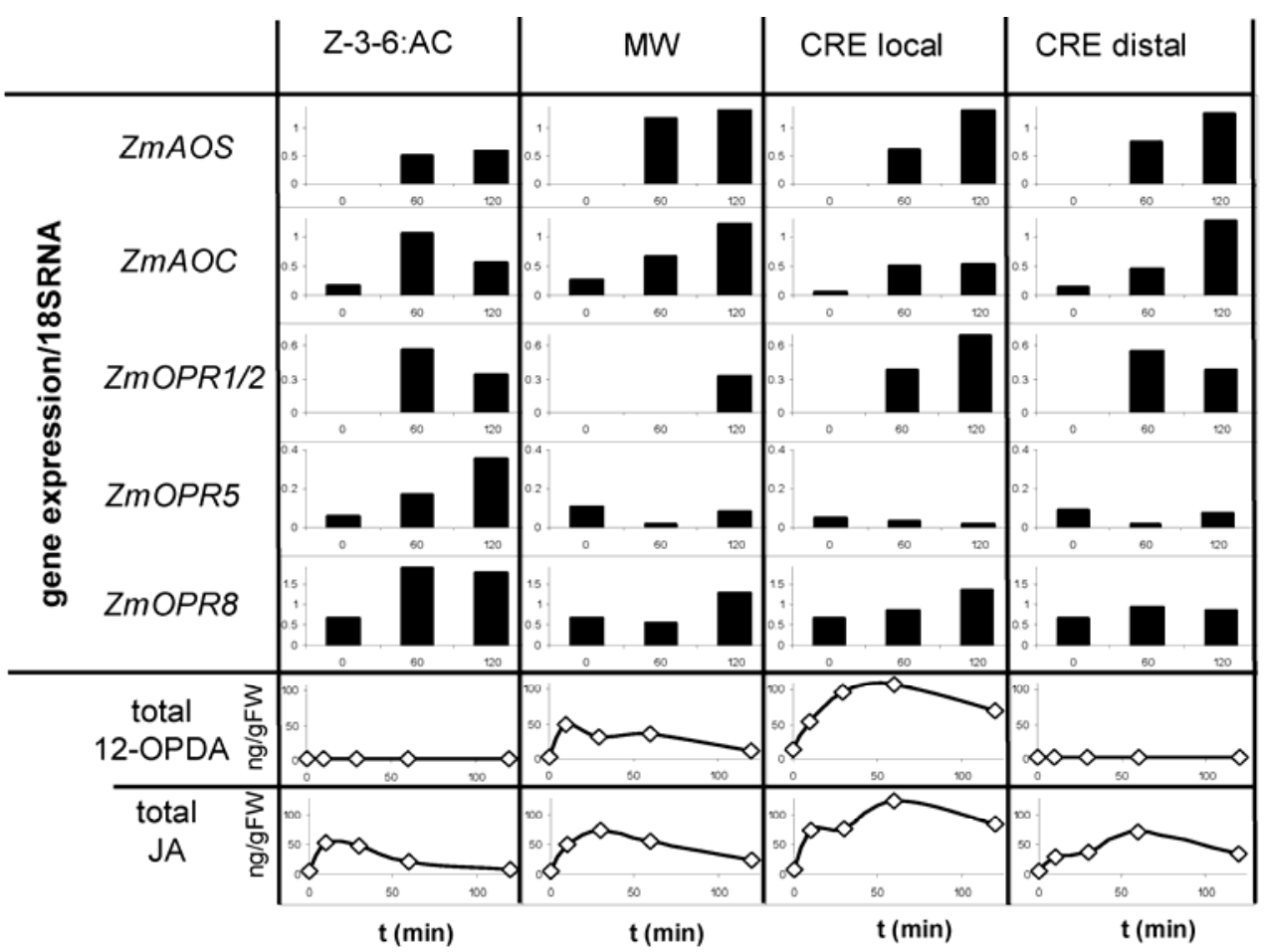

Fig. 6. Time course of gene expression (upper part) in Zea mays for ZmAOS, ZmAOC, and ZmOPR1/2,- 5, and -8 after exposure to Z-3-6:AC, mechanical wounding (MW), and application of crude regurgitant elicitors (CRE, local and distal). A typical result is shown. For better interpretation, time courses of total 12-oxo-phytodienoic acid (12-OPDA) and jasmonic acid (JA) were added (lower part). Gene expression is shown as polymerase chain reaction product/18S RNA. For gene expression analysis after exposure to Z-3-6:AC, corresponding segments were taken as for CRE application and for wound response. All experiments have been performed at least four times with biological triplicates and confirmed the above shown data.

Table 1. Comparison of ZmOPR gene expression shown in Zhang and associates (2005) and this study after various treatments

\begin{tabular}{|c|c|c|c|c|c|c|c|c|c|}
\hline \multirow[b]{3}{*}{ ZmOPR identification } & \multirow[b]{3}{*}{ ZmOPR no. } & \multicolumn{8}{|c|}{ Treatments $^{\mathrm{a}}$} \\
\hline & & \multicolumn{4}{|c|}{ Zhang et al. } & \multicolumn{4}{|c|}{ This study } \\
\hline & & MW & PI & $\mathbf{S A}$ & JA & GLV & MW & CRE local & CRE dista \\
\hline AY921638 & 1 & - & + & + & - & NA & NA & NA & NA \\
\hline AY921639 & 2 & - & + & + & - & ++ & + & ++ & ++ \\
\hline AY921640 & 3 & - & - & - & - & - & - & - & - \\
\hline AY921641 & 4 & - & - & - & - & - & - & - & - \\
\hline AY921642 & 5 & - & - & - & - & ++ & - & - & - \\
\hline AY921643 & 6 & + & - & - & + & - & - & - & - \\
\hline AY921644 & 7 & + & - & - & + & - & - & - & - \\
\hline AY921645 & 8 & + & - & - & + & ++ & + & + & - \\
\hline
\end{tabular}

${ }^{a}$ MW, mechanical wounding; PI, pathogen infection; SA, salicylic acid; JA, jasmonic acid; GLV, green leafy volatiles (here: Z-3-6:AC); CRE, crude regurgitant elicitor; +, increase of RNA levels; ++, strong increase of RNA levels; - , no increase; NA, not applicable. Due to the high identity between ZmOPRI and $2(96.5 \%)$ we were not able to design specific primers which could clearly distinguish between these two OPRs. 
Kessler et al. 2006). Corn seedlings (Engelberth et al. 2004) and tobacco plants (Kessler et al. 2006) that were exposed to physiological amounts of GLV respond to subsequent attack by insect herbivores faster and stronger with respect to defensive measures when compared with unexposed control plants. These priming responses, as well as most of the other more direct countermeasures, are thought to be signaled by JA through the activation of the octadecanoid signaling pathway.

However, this is not the only function of this pathway. Intermediates as well as the end product of the pathway also are involved in developmental processes, regulation of metabolism, perception of mechanical stimuli, and as signals in the wound response (Creelman and Mullet 1997; Wasternack and Hause 2002). The activation of the octadecanoid signaling pathway by wounding is probably the best investigated event among those chosen for this study. Wounding has been described at a molecular and a biochemical level to activate the whole pathway leading to JA in various plant species (Schaller 2001; Strassner et al. 2002; Wasternack and Hause 2002). As shown herein, increases in JA could not be detected either distal or basal from the site of wounding. Similarly, 12-OPDA increases occurred only locally. No increases in 12-OPDA levels were detected distal or basal from the site of mechanical wounding (data not shown). It appears that, in response to mechanical wounding, the area of octadecanoid activation was limited to the site of actual damage and the immediate adjacent tissue in corn seedlings. This is in accordance with data obtained from the Arabidopsis wound response, which also seems to be a local event, not only at the hormone level, measured as JA and 12-OPDA, but also at a molecular level. Strassner and associates (2002) showed that the expression of those genes related to JA biosynthesis is upregulated only around the wounding site.

The induction of the octadecanoid signaling pathway in response to insect herbivory, in addition to being caused by mechanical damage, is also affected significantly by elicitors in the oral secretions of the herbivores (Alborn et al. 1997; Schmelz et al. 2001). Application of both CRE and volicitininduced signaling events not only enhanced the local wound response (as indicated by increased JA and 12-OPDA production when compared with mechanical damage alone) but also caused the induction of JA in distal tissues of the affected leaf. This, however, occurred without the concomitant induction of 12-OPDA. The effect seen distally appeared without any measurable delay compared with local events. It does not look as if

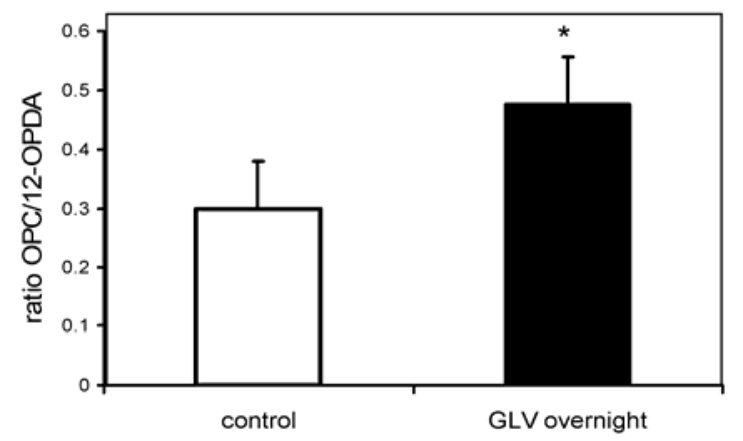

Fig. 7. Activity of 12-oxo-phytodienoate 10,11-reductase (OPR) enzymes in crude protein extracts from corn leaves. Protein was extracted in $50 \mathrm{mM}$ phosphate buffer, $\mathrm{pH}$ 7.4. OPR activity was estimated according to the protocol of Schaller and Weiler (1997b) with racemic 12-oxo-phytodienoic acid (12-OPDA) as substrate and NADPH as co-factor. Activity is expressed as changes in the ratio of 10,11 dihydro 12-oxophytodienoic acid (OPC) production and 12-OPDA consumption. GLV = green leafy volatiles. Results are based on two independent studies, each performed with four biological replicates. Error bars represent standard deviation. A Student $t$ test was used for proof of significance $(*, P \leq 0.05)$. it was related to a sink-source relationship, because leaves of all ages responded this way (data not shown). Rather, it appears to be related to a specific kind of signaling induced by these elicitors, which does not seem to involve active transport of JA from the local to the distal part of the leaf (data not shown), as has been described for systemic signaling in tomato (Schilmiller and Howe 2005). The induction of JA distal from the site of elicitor application without concomitant induction of 12-OPDA might represent one of the factors explaining the significantly different responses of plants to actual insect herbivory when compared with mechanical damage. Among these differences were stronger responses (Schmelz et al. 2001), different gene induction (Reymond et al. 2000), and the induction of defensive measures in other parts of the plant referred to as systemic signaling (Turlings and Tumlinson 1992). It must be stated that the signaling herein referred to as distal signaling is not to be confused with systemic signaling as described elsewhere (Schilmiller and Howe 2005).

The recently discovered activity of GLV toward the induction of JA added to the list of stimuli that interact with the octadecanoid signaling pathway (Engelberth et al. 2004). Not only did exposure to GLV induce JA accumulation in corn seedlings, it also prepared them against impending insect herbivory expressed as increased JA production and VOC release when induced with CRE or, as shown herein, with pure volicitin. On the other hand, no effect of priming by GLV on wound-induced JA accumulation or JA induced by a second application of GLV was observed, indicating a certain specificity of the GLV signal. Additionally, the fact that elevated JA levels were not accompanied by a concomitant increase of 12-OPDA bears close resemblance to the observed JA accumulation after CRE application in distal parts of the leaf and might be part of the specific linking between these two events. It also suggested that either a highly regulated turnover or a conjugated precursor within the pathway leading to the biosynthesis of JA exists, which does not allow for any free intermediate of the pathway to be detected. However, experiments performed to detect conjugated 12-OPDA or JA (e.g., in the form of lipids as described by Stelmach and associates [2001] for 12-OPDA or amino acid conjugates of JA) failed to produce any evidence for this kind of precursor.

The induction of 12-OPDA only in response to mechanical damage strongly suggests a specific role for this important intermediate in the wound response. Indeed, 12-OPDA has the capacity to induce defense-related genes in the absence of JA (Stintzi et al. 2001). Additionally, 12-OPDA has been shown to specifically affect transcript levels of certain genes different from those induced by JA, but typical for the wound response (Taki et al. 2005). Therefore, 12-OPDA has to be considered a wound signal, and its accumulation is enhanced in the presence of insect elicitors. In addition to being powerful stress and defense gene inducers and, thus, playing an active role in the plant defense response (Weber et al. 2004), alternative functions for compounds like 12-OPDA, trans-2-hexenal, traumatin, and other small molecules with an $\alpha, \beta$-unsaturated carbonyl need to be contemplated. Prost and associates (2005) investigated the antimicrobial properties of plant-derived oxylipins. Among the compounds that exhibit a high activity against various bacterial and fungal pathogens were those well known to be upregulated at the site of mechanical damage, such as GLV and 12-OPDA. For example, cis-3- and trans-2-hexenal had a strong growthinhibiting activity of bacterial pathogens, and 12-OPDA was most effective against fungal growth as well as germination of oomycete spores. These results strongly suggest additional functions for these compounds in the immediate protection against invading pathogen in those areas bare of mechanical barriers. Concurrently, by serving as Michael acceptors, the same compounds can cause significant cell damage by modifying en- 
zymes involved in signal transduction or affecting DNA integrity (Almeras et al. 2003; Parola et al. 1999; Vollenweider et al. 2000). Therefore, the regulation of these compounds is of critical importance for the cell. Although first thought to be involved in JA biosynthesis, 12-oxo-phytodienoic acid reductases (OPR) currently are being discussed as major regulators in this process (Schaller et al. 2004).

As shown herein, exposure to Z-3-6:AC significantly increased the transcript levels of three different putative 12-oxophytodienoate 10,11-reductase genes (ZmOPRI/2, ZmOPR5, and $Z m O P R 8)$. ZmOPR5 transcript levels were exclusively affected by exposure to GLV, whereas $Z m O P R 1 / 2$ also was responsive to the application of CRE. ZmOPR8 transcript levels were increased at the site of mechanical wounding but not in the distal part of the leaf after CRE application. Induction of ZmOPR8 after wounding and CRE application could be due to the immediate release of GLV rather than being a specific response to these treatments. This also could explain the induction of $Z m O P R 1 / 2$ in response to mechanical damage and CRE application to the wounded a site. However, the induction of $Z m O P R l / 2$ in the distal part of the leaf has to be considered as a process independent of GLV action because GLV are not increased in this area during the period covered in this experiment (J. Engelberth, unpublished data). Interestingly, ZmOPRI/2 was reported by Zhang and associates (2005) to be inducible by pathogen infection and SA, a process commonly thought to have an inhibitory effect on JA-related processes (Beckers and Spoel 2006; Engelberth et al. 2001). However, as shown herein, transcript levels of $Z m O P R I / 2$ also were increased by CRE application, which significantly affected the JA pathway in corn but not SA-related signaling (data not shown). Therefore, a general role of $Z m O P R 1 / 2$ in the defense response has to be considered. A synopsis of the results from Zhang and associates (2005) and our own data on the expression of $Z m O P R$ genes is shown in Table 1. A major discrepancy between those results concerns the transcript levels of ZmOPR6 and ZmOPR7, which have been shown by Zhang and associates (2005) to be inducible by mechanical wounding. In contrast, in our hands, wounding did not increase the RNA levels for those genes. Reasons for the differences in the transcript levels of ZmOPR6 with respect to mechanical damaging could lie in the different corn cultivar used for the respective study, the mode of mechanical damage, and, most importantly, a different timing of the experiment. Additionally, due to the high identity between $\mathrm{ZmOPR} 7$ and -8 , Zhang and associates (2005) were not able to generate a gene-specific probe and, therefore, could not clearly distinguish between the two $O P R$ s, whereas we used gene-specific primers.

It appears that GLV can act as a major regulator for the induction of $O P R$ genes in corn. Also, OPR activity is significantly increased after $15 \mathrm{~h}$ of exposure to GLV, at a time when the priming effect is most prominent (Engelberth et al. 2004). This increase in activity might account for a higher turnover activity when challenged with insect-derived elicitors, resulting in elevated JA levels when compared with equally challenged non-GLV-exposed plants. However, the actual functions and the physiological consequences of $O P R$ induction in corn by GLV have yet to be established. A thorough characterization of individual $\mathrm{ZmOPR}$ proteins is needed to allow for the correct pathway-specific allocation of the respective enzyme. Work in our lab currently is focusing on the biochemical characterization of these enzymes.

\section{MATERIALS AND METHODS}

\section{Chemicals.}

Cis-3-hexen-1-yl acetate (Z-3-6:AC) (98\% pure), and NADPH were purchased from Sigma-Aldrich, St. Louis,
U.S.A. Racemic 12-OPDA was purchased from Larodan Fine Chemicals, Malmö, Sweden. Dihydro jasmonic acid-methyl ester (Bedoukian Research, Danbury, CT, U.S.A.) was converted to dihydro jasmonic acid (dhJA) by alkaline hydrolysis. All solvents used were analytical grade.

\section{Plant material.}

Corn seed (Z. mays var. Kandy King and Bonus) were purchased from J. W. Jung Seed Co., Randolph, WI, U.S.A. and grown as described previously (Schmelz et al. 2001).

\section{Preparation of CRE from larvae of beet armyworm.}

Beet armyworm (BAW) were transferred to feed on corn seedlings at least $48 \mathrm{~h}$ before collection of regurgitant. Regurgitation was induced by holding fourth-instar beet armyworm caterpillars with forceps and gently pinching behind the head with a second pair. The regurgitant from 40 to 50 caterpillars was collected, boiled for $5 \mathrm{~min}$ to inactivate degrading enzymes (Mori et al. 2001), and centrifuged to remove cell debris and denatured proteins, and the supernatant was diluted $1: 1$ in buffer $\left(50 \mathrm{mM} \mathrm{NaPO}_{4}, \mathrm{pH} 8\right)$ prior to use (referred to as CRE).

\section{Plant treatments.}

As described previously (Engelberth et al. 2004), the release rates of GLV from corn leaves were measured after mechanical damage and insect herbivory. Also, GLV do adsorb to the surface of the containers, and concentrations rapidly decrease over a period of $1 \mathrm{~h}$. Based on those results, the amounts used for this study were calculated and were within the physiological range over the duration of the treatments. To avoid crosscontamination between experiments, the Plexiglas containers were washed with soap and water after each experiment. Additionally, the containers were rinsed with methanol and air dried. No residual GLV from previous treatments were detected after this procedure, as detected by gas chromatography/mass spectrometry (GC/MS). To measure the short-term production of JA and 12-OPDA, intact corn plants (receiver plants) were exposed to Z-3-6:AC in 6-liter Plexiglas cylinders. One hundred $\mu \mathrm{g}$ (dissolved in dichloromethane, $1 \mu \mathrm{g} / \mu \mathrm{l}$ ) were pipetted onto a cotton ball in the Plexiglas cylinder. Controls consisted of a plant in a chamber with $100 \mu \mathrm{l}$ of pure dichloromethane on a cotton ball. After $0,10,30,60$, and $120 \mathrm{~min}$, the intact receiver plants were removed from the chamber and the leaves frozen in liquid nitrogen for further analysis. The second leaf of each seedling was harvested and immediately frozen in liquid $\mathrm{N}_{2}$ for further processing.

For induction with CRE, an area of approximately 2 by 10 $\mathrm{mm}$ on the third leaf of intact corn plants was scratched with a razor blade and $10 \mu \mathrm{l}$ of CRE from BAW immediately was added to the wounded site. Similarly, volicitin was applied to corn seedlings at a final concentration of $1 \mathrm{nmol}$ per damaged site and plant. The amounts of volicitin used for this study correspond to those seen in CRE. Additionally, other FAC-like $N$ linolenoyl glutamine also were active, so that the actual amount of active elicitors in the CRE was higher. For wounding, a corresponding section of the third leaf was scratched as described above and $10 \mu \mathrm{l}$ of buffer $\left(25 \mathrm{mM} \mathrm{NaPO}_{4}, \mathrm{pH} 8\right)$ was added to the wounded site. Sections of approximately 2.5 $\mathrm{cm}$ were taken from the wounded site (local) and distal (leaf upward) as well as basal from the wound site for analysis. These sections were harvested at various times after wounding and application of CRE, and analyzed for JA, 12-OPDA, and defense gene RNA levels by semiquantitative PCR (discussed below). For the analysis of corn leaves exposed to Z-3-6:AC, corresponding leaf sections of each plant were taken to allow for exact comparison. 
For overnight exposure to synthetic compounds, $100 \mu \mathrm{g}$ of Z-3-6:AC (dissolved in dichloromethane, $1 \mu \mathrm{g} / \mu \mathrm{l}$ ) was pipetted onto a cotton ball in the Plexiglas cylinder. For controls, 100 $\mu l$ of dichloromethane was added to the cotton ball.

For induction with CRE, by wounding, or a second application of Z-3-6:AC, intact corn plants were removed from the Plexiglas cylinders after $15 \mathrm{~h}$ and treated as follows. CRE was applied as described above and leaves were harvested after 30 min. Mechanical wounding was performed accordingly without any further treatment. For a second exposure to GLV, Z-36:AC plants were removed from the container for $1 \mathrm{~h}$ and then exposed for $20 \mathrm{~min}$ as described above. JA was quantified as described below.

\section{Quantification of JA and 12-OPDA.}

Extraction and quantification of JA and 12-OPDA was performed as described previously (Engelberth et al. 2004). In brief, plant tissues were frozen in liquid $\mathrm{N}_{4}$ and approximately $100 \mathrm{mg}$ of each sample was transferred to 2-ml screw-cap FastPrep tubes (Qbiogene, Carlsbad, CA, U.S.A.) containing $1 \mathrm{~g}$ of Zirmil beads $(1.1 \mathrm{~mm}$; SEPR Ceramic Beads and Powders, Mountainside, NJ, U.S.A.). dhJA and $\left[{ }^{2} \mathrm{H}_{6}\right]$ SA (100 ng) were added to the 2-ml tubes prior to sample addition. The samples were mixed with $300 \mu \mathrm{l}$ of 1 -propanol/ $/ \mathrm{H}_{2} \mathrm{O} / \mathrm{HCl}$ (2:1:0.002) and shaken for $30 \mathrm{~s}$ in a FastPrep FP 120 tissue homogenizer (Qbiogene). Dichloromethane $(1 \mathrm{ml})$ was added to each sample, reshaken for $10 \mathrm{~s}$ in the homogenizer, and centrifuged at $11,300 \times$ $g$ for $30 \mathrm{~s}$. The bottom dichloromethane:1-propanol layer then was transferred to a 4-ml glass screw-cap vial, with care taken to avoid transfer of the upper aqueous layer. The organic phase was evaporated by a constant air stream and $100 \mu \mathrm{l}$ of diethyl ether/methanol (9:1, vol/vol) was added. Carboxylic acids were converted into methyl-esters by the addition of $2 \mu \mathrm{l}$ of a $2.0-\mathrm{M}$ solution of trimethylsilyldiazomethane in hexane. The vials then were capped, vortexed, and allowed to sit at room temperature for $30 \mathrm{~min}$. Excess trimethylsilyldiazomethane then was destroyed by adding $2 \mu \mathrm{l}$ of $2 \mathrm{M}$ acetic acid in hexane to each sample. Volatile metabolites were separated from the complex mixture by vapor phase extraction as described by Engelberth and associates (2003). The trapped volatiles then were eluted with $150 \mu \mathrm{l}$ of dichloromethane and analyzed by GC/MS (Engelberth et al. 2003; Schmelz et al. 2003). Because appropriate internal standards are not commercially available, 12-OPDA was quantified by comparison with an external standard curve as described previously (Schmelz et al. 2003).

\section{Extraction of RNA and semiquantitative RT-PCR.}

Total RNA was extracted from corn leaves (approximately $50 \mathrm{mg} \mathrm{FW}$ ) after various treatments as described above with the Qiagen RNeasy Plant Kit according to the manufacturer's instructions, with the following modifications. Frozen plant samples were homogenized in 2-ml, screw-cap FastPrep tubes containing $0.5 \mathrm{~g}$ of Zirmil microbeads for $10 \mathrm{~s}$ at grade 6 in a FastPrep FP 120 tissue homogenizer. After adding $450 \mu \mathrm{l}$ of RLT buffer (with $\beta$-mecaptoethanol added according to the manufacturer's instructions), the samples were mixed again for $20 \mathrm{~s}$ at grade 6 . The extract was transferred to a shredder column, then further processed as described in the manufacturer's instructions. DNase treatment was performed after extraction of RNA with the Turbo DNA free kit (Ambion, Austin, TX, U.S.A.) according to the manufacture's instructions. Reverse transcription of $1.5 \mu \mathrm{g}$ (in $12 \mu \mathrm{l}$ of water) of DNA-free RNA was performed in a final volume of $20 \mu \mathrm{l}$ with $5 \mathrm{mM}$ oligo dTs, $5 \mathrm{mM}$ random octamers, $1 \times$ RT buffer, $500 \mu \mathrm{M}$ (each) dNTPs, $10 \mathrm{U}$ of RNase inhibitor, and $0.25 \mathrm{U}$ of reverse transcriptase (Omniscript kit; Qiagen). The reaction mixture was incubated for $90 \mathrm{~min}$ at $37^{\circ} \mathrm{C}$. For semiquantitative analysis, the cDNA was diluted $(1: 10)$ and $5 \mu$ from this dilution was used for PCR. Because ZmOPRI and -2 are $96.5 \%$ identical at the nucleotide level, we were unable to design specific primers that enabled us to distinguish between these two RNA sequences. Both $Z m O P R 1$ and $Z m O P R 2$ would be amplified and amplicons could consist of a mixture of ZmOPRl and -2. Although cloning and sequencing of the amplified PCR products was performed for sequence confirmation, we still were not able to clearly attribute the obtained sequences to either ZmOPR1 or ZmOPR2. Due to this, PCR products obtained by using this primer combination were referred to as $Z m O P R 1 / 2$. Primers were used as follows: allene oxide synthase $(Z m A O S$, AY 104188.1) forward primer 5'-AAGGTGCAGGAGCTGTA CG-3', reverse primer 5'-CAGGTACGACTCCTCGTAGGT-3'; allene oxide cyclase (ZmAOC, AY 103942.1) forward primer 5'-GACCGCCTCGACTTCTACTAC-3', reverse primer 5'-GA AGAGCAGCTGCTTCACCTT-3' (for AOS and AOC, Frey et al. 2004); 12-oxo-phytodienoic acid reductase ZmOPR5, (TC 251210) forward primer 5'-ATCAGCAGAGGGCGACTAAA$3^{\prime}$ (corresponding to position 146 to 165 ), reverse primer $5^{\prime}$ CGAGCAGCTACCCTGAAATC-3' (position 487 to 506); ZmOPRl/2 (based on TC 249880) forward primer 5'-AACAA ATACGACCGCTCCAC-3' (position 1,179 to 1,199), reverse primer 5'-CCAATAGACAATGGCACACG-3' (position 1,526 to 1,545); and ZmOPR8 (TC 261920) forward primer 5'-ACG CTGACCTGGTGTCCTAC-3' (position 432 to 453), reverse primer 5'-GGCATTACCCAGATGTTTGC-3' (position 677 to 697). ZmOPR6 and -7 primers were taken from TC 251596 (forward primer 5'-AAATCCCAGCACAGGTGAAC-3' [position 431 to 450], reverse primer 5'-TCTCGTCGATGACATGA AGC-3' [position 795 to 814]) and TC 238776 (forward primer 5'-CATTTCCCTCTCCAACTCCA-3' [position 165 to 191], reverse primer 5'-TTCCATGCATCAGTCTGCTC-3' [position 465 to 484]), respectively. Primers for $\mathrm{ZmOPR3}$ and $\mathrm{ZmOPR} 4$ were taken from AY921640 (forward primer 5'-CAACCCA GACCTGCCTAAAA-3' [position 1,051 to 1,070], reverse primer 5'-CGATCTCGATCGTGCAGTAA-3' [position 1,226 to 1,245$]$ ) and AY921641 (forward primer 5'-TTTGAACGGA AAGACCTTGG-3' [position 277 to 296], reverse primer 5'AGTCGACGATGATGATGC-3' [position 498 to 517]). The primers for the internal standard 18S RNA was taken from OG ZAF25TV. The following primers were used: forward $5^{\prime}$ CGGCTACCACATCCAAGGAA-3' and reverse 5'-TGCTGG CACCAGACTTGCCCTC-3', corresponding to positions 262 to 281 and 409 to 429 , respectively. The PCR volume was 20 $\mu \mathrm{l}$, consisting of $1 \times$ green GoTaq buffer (Promega Corp., Madison, WI, U.S.A.), $1.5 \mathrm{mM} \mathrm{MgCl} 2,0.4 \mathrm{mM}$ dNTPs, $1 \mu \mathrm{M}$ primers, 18S:competimer (1:9, $0.15 \mu \mathrm{l})$ (QuantumRNA 18S Internal Standards, Ambion), $1 \mathrm{U}$ of GoTaq polymerase, 0.07 mM TagStart antibody (BD Biosciences, San Jose, CA, U.S.A.), and $0.8 \mu \mathrm{l}$ of antibody dilution buffer (BD Biosciences). PCR was performed on a Stratagene Robocycler. The following program was used for amplification: $95^{\circ} \mathrm{C}$ for $3 \mathrm{~min}$; then 27 cycles of $94^{\circ} \mathrm{C}$ for $30 \mathrm{~s}, 54^{\circ} \mathrm{C}$ for $30 \mathrm{~s}$, and $68^{\circ} \mathrm{C}$ for $1 \mathrm{~min}$; and finally $68^{\circ} \mathrm{C}$ for $7 \mathrm{~min}$. The ratio of $18 \mathrm{~S}$ to competimer was adjusted so that the linear amplification ranges for both genes, the gene of interest and $18 \mathrm{~S}$, overlapped in the duplex PCR. We chose a cycle common to both linear ranges as the endpoint cycle for the duplex PCR. The PCR products $(10 \mu \mathrm{l})$ were separated on a $1.5 \%$ agarose gel for analysis. Ethidiumbromide-stained bands were analyzed with a Kodak image station $440 \mathrm{CF}$ and normalized by comparison with 18S rRNA. Each experiment was performed at least in triplicate. The amplified fragments for corn $Z m O P R$ were cloned with the TOPOTA cloning kit from Invitrogen (Carlsbad, CA, U.S.A.). Individual colonies were picked and plasmids were sequenced for sequence confirmation. 


\section{Activity of OPR enzymes in crude protein extracts from corn leaves.}

Protein was extracted in $50 \mathrm{mM}$ potassium phosphate buffer, $\mathrm{pH}$ 7.4. OPR activity was estimated according to the protocol of Schaller and Weiler (1997a and b) with racemic 12-OPDA as substrate and NADPH as co-factor. Activity is expressed as changes in ratio between OPC and 12-OPDA.

\section{Statistical analysis.}

At least three biological replicates of all experiments were performed. Data were analyzed for significance with the Student $t$ test $(P<0.05)$. Treatments were compared with appropriate controls.

\section{ACKNOWLEDGMENTS}

We thank E. Engelhard and M. Lobaido for their technical support. We would also like to thank the United States Department of Agriculture-Agricultural Research Service, the Center for Medical, Agricultural, and Veterinary Entomology, and Department of Chemistry, Gainesville, FL for their partial support of this project through a specific cooperative agreement.

\section{LITERATURE CITED}

Alborn, H. T., Turlings, T. C., Jones, T. H., Stenhagen, G. S., Loughrin, J. H., and Tumlinson, J. H. 1997. An elicitor of plant volatiles identified from beet armyworm oral secretions. Science 276:945-949.

Almeras, E., Stolz, S., Vollenweider, S., Reymond, P., Mene-Saffrane, L., and Farmer, E. E. 2003. Reactive electrophile species activate defense gene expression in Arabidopsis. Plant J. 34:205-216.

Arimura, G., Ozawa, R., Shimoda, T., Nishioka, T., Boland, W., and Takabayashi, J. 2000. Herbivory-induced volatiles elicit defense genes in lima bean leaves. Nature 406:512-515.

Bate, N. J., and Rothstein, S. J. 1998. C6-volatiles derived from the lipoxygenase pathway induce a subset of defense-related genes. Plant J. $16: 561-569$

Beckers, G. J. M., and Spoel, S. H. 2006. Fine-tuning plant defense signaling: Salicylate versus jasmonate. Plant Biol. 8:1-10.

Biesgen, C., and Weiler, E. W. 1999. Structure and regulation of OPR1 and $O P R 2$, two closely related genes encoding 12-oxophytodienoic acid10,11-reductases from Arabidopsis thaliana. Planta 208:155-165.

Breithaupt, C., Strassner, J., Breitinger, U., Huber, R., Macheroux, P., Schaller, A., and Clausen, T. 2001. X-ray structure of 12-oxophytodienoate reductase 1 provides structural insight into substrate binding and specificity within the family of OYE. Structure 9:419-429.

Creelman, R. A., and Mullet, J. E. 1997. Biosynthesis and action of jasmonates in plants. Annu. Rev. Plant. Physiol. Plant Mol. Biol. 48:355381.

Croft, K. P. C., Juttner, F., and Slusarenko, A. J. 1993. Volatile products of the lipoxygenase pathway evolved from Phaseolus vulgaris (L.) leaves inoculated with Pseudomonas syringae pv. phaseolicola. Plant Physiol. 101:13-24.

Cruz Castillo, M., Martinez, C., Buchala, A., Metraux, J. P., and Leon, J. 2004. Gene-specific involvement of $\beta$-oxidation in wound-activated responses in Arabidopsis. Plant Physiol. 135:85-94.

De Moraes, C. M., Mescher, M. C., and Tumlinson, J. H. 2001. Caterpillar-induced nocturnal plant volatiles repel conspecific females. Nature 410:577-580.

Dicke, J., van Beek, T. A., Posthumus, M. A., Ben Dom, N., Van Bokhoven, H., and De Groot, A. E. 1990. Isolation and identification of volatile kairomone that affects acarine predator-prey interactions. Involvement of host plant in its production. J. Chem. Ecol. 16:381-396.

Engelberth, J., Koch, T., Schuler, G., Bachmann, N., Rechtenbach, J., and Boland, W. 2001. Ion channel-forming alamethicin is a potent elicitor of volatile biosynthesis; cross-talk between jasmonate- and salicylate signaling in the lima bean. Plant Physiol. 125:369-377.

Engelberth, J., Schmelz, E. A., Alborn, H. T., Cardoza, Y. J., Huang, J., and Tumlinson, J. H. 2003. Simultaneous quantification of jasmonic acid and salicylic acid in plants by vapor phase extraction and gas chromatography-chemical ionization-mass spectrometry. Anal. Biochem. 312:242-250

Engelberth, J., Alborn, H. T., Schmelz, E. A., and Tumlinson, J. H. 2004. Airborne signals prime plants against herbivore attack. Proc. Natl. Acad. Sci. U.S.A. 101:1781-1785.

English, J., and Bonner J. 1937. The wound hormones of plants. I.
Traumatin, the active principle of the bean test. J. Biol. Chem. 121:791 799.

Farag, M. A., and Pare, P. W. 2002. C $_{6}$-green leaf volatiles trigger local and systemic VOC emissions in tomato. Phytochemistry 61:545-554.

Farag, M. A., Fokar, M., Abd, H., Zhang, H., Allen, R. D., and Pare, P. W. 2005. (Z)-3-Hexenol induces defense genes and downstream metabolites in maize. Planta 220:900-909.

Frey, M., Spiteller, D., Boland, W., and Gierl, A. 2004. Transcriptional activation of $\mathrm{Igl}$, the gene for indole formation in Zea mays: A structureactivity study with elicitor-active $N$-acyl glutamines from insects. Phytochemistry 65:1047-1055.

Gatehouse, J. A. 2002. Plant resistance towards insect herbivores: A dynamic interaction. New Phytol. 156:145-169.

Halitschke, R., Schittko, U., Pohnert, G., Boland, W., and Baldwin, I. T. 2001. Molecular interactions between the specialist herbivore Manduca sexta (Lepidoptera, Sphingidae) and its natural host Nicotiana attenuata. III. Fatty acid-amino acid conjugates in herbivore oral secretions are necessary and sufficient for herbivore-specific plant responses. Plant Physiol. 125:711-717.

Halitschke, R., Ziegler, J., Keinanen, M., and Baldwin, I. T. 2004. Silencing of hydroperoxide lyase and allene oxide synthase reveals substrate and defense signaling crosstalk in Nicotiana attenuata. Plant J. 40:3546.

Hatanaka, A. 1993. The biogeneration of green odour by green leaves. Phytochemistry 34:1201-1218.

Hildebrand, D. F., Brown, G. C., Jackson, D. M., and Hamilton-Kemp, T. R. 1993. Effects of some leaf-emitted volatile compounds on aphid population increase. J. Chem. Ecol., 19:1875-1887.

Kessler, A., Halitschke, R., Dieyel, C., and Baldwin, I. T. 2006. Priming of plant defense responses in nature by airborne signaling between $\mathrm{Ar}$ temisia tridentata and Nicotiana attenuata. Oecologia 148:280-292.

Kishimoto, K., Matsui, K., Ozawa, R., and Takabayashi, J. 2005. Volatile C6-aldehydes and allo-ocimene activate defense genes and induce resistance against Botrytis cinera in Arabidopsis thaliana. Plant Cell Physiol. 46:1093-1102.

Laudert, M., and Weiler, E. W. 1998. Allene oxide synthase: A major control point in Arabidopsis thaliana octadecanoid signaling. Plant J. 15:675-684.

Li, C., Schilmiller, A. L., Liu, G., Lee, G. I., Jayanty, S., Sageman, C., Vrebalov, J., Giovannoni, J. J., Yagi, K., Kobayashi, Y., and Howe, G. A. 2005. Role of $\beta$-oxidation in jasmonate biosynthesis and systemic wound signaling in tomato. Plant Cell 17:971-986.

McCall, P. J., Turlings, T. C. J., Lewis, W. J., and Tumlinson, J. H. 1993. Role of plant volatiles in host location by the specialist parasitoid $\mathrm{Mi}$ croplitis croceipes Cresson (Braconidae: Hymenoptera). J. Insect Behav. 6:625-639.

McCall, P. J., Turlings, T. C. J., Loughrin, J. H., Proveaux, A. T., and Tumlinson, J. H. 1994. Herbivore-induced volatile emissions from cotton (Gossypium hirsutum L.) seedlings. J. Chem. Ecol. 20:3039-3050.

Mori, N., Alborn, H. T., Teal, P. E., and Tumlinson, J. H. 2001. Enzymatic decomposition of elicitors of plant volatiles in Heliothis virescens and Helicoverpa zea. J. Insect Physiol. 47:749-757.

Pare, P. W., and Tumlinson, J. H. 1997. De novo biosynthesis of volatiles induced by insect herbivory in cotton plants. Plant Physiol. 114:11611167

Pare, P. W., and Tumlinson, J. H. 1999. Plant volatiles as a defense against insect herbivores. Plant Physiol. 121:325-331.

Parola, M., Bellomo, G., Robino, G., Barrera, G., and Dianzani, M. U. 1999. 4-Hydroxynonenal as a biological signal: Molecular basis and pathophysiological implications. Antioxid. Redox Signal. 1:255-284.

Prost, I., Dhondt, S., Rothe, G., Vicente, J., Rodriguez, M. J., Kift, N., Carbonne, F., Griffiths, G., Esquerre-Tugaye, M. T., Rosahl, S., Castresana, C., Hamberg, M., and Fournier, J. 2005. Evaluation of the antimicrobial activities of plant oxylipins supports their involvement in defense against pathogens. Plant Physiol. 139:1902-1913.

Reymond, P., Weber, H., Damond, M., and Farmer, E. E. 2000. Differential gene expression in response to mechanical wounding and insect feeding in Arabidopsis. Plant Cell 12:707-719.

Röse, U. S. R., Manukian, A., Heath, R. R., and Tumlinson, J. H. 1996. Volatile semiochemicals released from undamaged cotton leaves: A systemic response of living plants to caterpillar damage. Plant Physiol. 111:487-495.

Ruther, J., and Fürstenau, B. 2005. Emission of herbivore-induced volatiles in absence of a herbivore-response of Zea mays to green leaf volatiles and terpenoids. Z. Naturforsch. 60:743-756.

Ruther, J., and Kleier, S. 2005. Plant-plant signaling: Ethylene synergizes volatile emission in Zea mays induced by exposure to (Z)-3-hexen-1-ol. J. Chem. Ecol. 31:2217-2222.

Schaller, F. 2001. Enzymes of the biosynthesis of octadecanoid-derived signaling molecules. J. Exp. Bot. 52:11-23. 
Schaller, F., and Weiler, E. W. 1997a. Enzymes of octadecanoid biosynthesis in plants-12-oxo-phytodienoate 10,11-reductase. Eur. J. Biochem. 15:294299.

Schaller, F., and Weiler, E. W. 1997b. Molecular cloning and characterization of 12-oxophytodienoate reductase, an enzyme of the octadecanoid signaling pathway from Arabidopsis thaliana. Structural and functional relationship to yeast old yellow enzyme. J. Biol. Chem. 272:28066-28072.

Schaller, F., Biesgen, C., Mussig, C., Altmann, T., and Weiler, E. W. 2000 12-Oxophytodienoate reductase 3 (OPR3) is the isoenzyme involved in jasmonate biosynthesis. Planta 210:979-984.

Schaller, F., Schaller, A., and Stintzi, A. 2004. Biosynthesis and metabolism of jasmonates. J. Plant Growth Regul. 23:179-199.

Schilmiller, A. L., and Howe, G. A. 2005. Systemic signaling in the wound response. Curr. Opin. Plant. Biol. 8:369-377.

Schittko, U., Preston, C. A., and Baldwin, I. T. 2000. Eating the evidence? Manduca sexta larvae can not disrupt specific jasmonate induction in Nicotiana attenuata by rapid consumption. Planta 210:343-346.

Schmelz, E. A., Alborn, H. T., and Tumlinson, J. H. 2001. The influence of intact-plant and excised-leaf bioassay designs on volicitin- and jasmonic acid-induced sesquiterpene volatile release in Zea mays. Planta 214:171179.

Schmelz, E. A., Engelberth, J., Alborn, H. T., O’Donnell, P., Sammons, M., Toshima, H., and Tumlinson, J. H. 2003. Simultaneous analysis of phytohormones, phytotoxins, and volatile organic compounds in plants. Proc. Natl. Acad. Sci. U.S.A. 100:10552-10557.

Stelmach, B. A., Muller, A., Hennig, P., Gebhardt, S., Schubert-Zsilavecz, M., and Weiler, E. W. 2001. A novel class of oxylipins, sn1-O-(12-oxophytodienoyl)-sn2-O-(hexadecatrienoyl)-monogalactosyl diglyceride, from Arabidopsis thaliana. J. Biol. Chem. 276:12832-12838.

Stintzi, A., Weber, H., Reymond, P., Browse, J., and Farmer, E. E. 2001 Plant defense in the absence of jasmonic acid: The role of cyclopentenones. Proc. Natl. Acad. Sci. U.S.A. 98:12837-12842.

Strassner, J., Fürholz, A., Macheroux, P., Amrhein, N., and Schaller, A. 1999. A homolog of old yellow enzyme in tomato. J. Biol. Chem. 274:35067-35073.

Strassner, J., Schaller, F., Frick, U. B., Howe, G. A., Weiler, E. W. Amrhein, N., Macheroux, P., and Schaller, A. 2002. Characterization and cDNA-microarray expression analysis of 12-oxophytodienate reductase reveals differential roles for octadecanoid biosynthesis in the local versus the systemic wound response. Plant J. 32:585-601.
Taki, N., Sasaki-Sekimoto, Y., Obayashi, T., Kikuta, A., Kobayashi, K, Ainai, T., Yagi, K., Sakurai, N., Suzuki, H., Masuda, T., Takamiya, K., Shibata, D., Kobayashi, Y., and Ohta, H. 2005. 12-Oxo-phytodienoic acid triggers expression of a distinct set of genes and plays a role in wound-induced gene expression in Arabidopsis. Plant Physiol. 139:12681283.

Theodoulou, F. L., Job, K., Slocombe, S. P., Footitt, S., Holdsworth, M., Baker, A., Larson, T. R., and Graham, I. A. 2005. Jasmonic acid levels are reduced in COMATOSE ATP-binding cassette transporter mutants. Implications for transport of jasmonate precursors into peroxisomes. Plant Physiol. 137:835-840.

Turlings, T. C., and Tumlinson, J. H. 1992. Systemic release of chemical signals by herbivore-injured corn. Proc. Natl. Acad. Sci. U.S.A. 89:8399-8402.

Turlings, T. C. J., Tumlinson, J. H., and Lewis, W. J. 1990. Exploitation of herbivore-induced plant odors by host seeking parasitic wasps. Science 250:1251-1253

Turlings, T. C., Alborn, H. T., Loughrin, J. H., and Tumlinson, J. H. 2000. Volicitin, an elicitor of maize volatiles in oral secretion of Spodoptera exigua: Isolation and bioactivity. J. Chem. Ecol. 26:189-202.

Vollenweider, S., Weber, H., Stolz, S., Chetelat, A., and Farmer, E. E. 2000. Fatty acid ketodienes and fatty acid ketotrienes: Michael addition acceptors that accumulate in wounded and diseased Arabidopsis leaves. Plant J. 24:467-476.

Wasternack, C., and Hause, B. 2002. Jasmonates and octadecanoids: Signals in plant stress responses and development. Prog. Nucleic Acid Res. Mol. Biol. 72:165-221.

Weber, H., Chetelat, A., Reymond, P., and Farmer, E. E. 2004. Selective and powerful stress gene expression in Arabidopsis in response to malonyldialdehyde. Plant J. 37:877-888.

Zeringue, H. J. 1992. Effects of $\mathrm{C}_{6}-\mathrm{C}_{10}$ alkenals and alkanals on eliciting a defence response in the developing cotton boll. Phytochemistry 31:2305-2308.

Zhang, J., Simmons, C., Yalpani, N., Crane, V., Wilkinson, H., and Kolomiets, M. 2005. Genomic analysis of the 12-oxo-phytodienoic acid reductase gene family of Zea mays. Plant Mol. Biol. 59:323-343.

Ziegler, J., Stenzel, I., Hause, B., Maucher, H., Hamberg, M., Grimm, R., Ganal, M., and Wasternack, C. 2000. Molecular cloning of allene oxide cyclase. The enzyme establishing the stereochemistry of octadecanoids and jasmonates. J. Biol. Chem. 275:19132-19138. 